\title{
Streptomyces capillispiralis sp. nov.
}

\author{
F. P. MERTZ AND C. E. HIGGENS \\ The Lilly Research Laboratories, Eli Lilly \& Company, Indianapolis, Indiana 46285
}

\begin{abstract}
A Streptomyces isolate that produces a cephalosporin C-4 carboxymethyl esterase is proposed as a new species, Streptomyces capillispiralis. The key characteristics of this species are gray spore mass color, spiral spore chains, and hairy spores. When simultaneous laboratory comparisons were made with cultures of similar Streptomyces species, the new isolate differed from them significantly. The type strain of $S$. capillispiralis is A49492 $(=$ NRRL 12279). A separate paper dealing with the carboxymethyl esterase of this organism will be published in the future.
\end{abstract}

Strain A49492 was isolated in the course of a culture isolation program from a soil sample collected in Sweden. The organism differs significantly enough from other related species to warrant designation as a new species of the genus Streptomyces. Morphological and physiological data are reported to support recognition of a new species. A description of this organism and a discussion of its taxonomic position are also presented.

\section{MATERIALS AND METHODS}

Bacterial strains. Strain A49492 was isolated from a soil sample collected in Sweden. For comparative purposes, the following strains were also studied: $S$. flaveolus ATCC 3319 and "S. flavoviridis" ATCC 19903, which are strains from the Lilly culture collection; and $S$. calvus ATCC 13382, "S. heimi" ATCC 25460, "S. malachitofuscus" ATCC 25471, and S. pilosus ATCC 19797, which were obtained directly from the American Type Culture Collection (ATCC), Rockville, Md. (names in quotation marks are not on the Approved Lists of Bacterial Names [11] and have not been validly published as of 1 January 1980). These strains are the type strains of these species, as indicated in the Approved Lists (11) and the ATCC catalog 14th ed., except for that of "S. Alavoviridis," which is stated in the ATCC catalog to be the neotype.

Cell wall analyses. Cell wall analyses were performed on cultures grown in yeast-malt extract broth (ISP no. 2) (10) for $24 \mathrm{~h}$ at $30^{\circ} \mathrm{C}$. The mycelia were collected by centrifugation and were washed three times with distilled water. The washed cells were then freeze-dried. The cell wall sugars were determined by a modification of the procedure of Lechevalier (8). Diaminopimelic acid isomers were determined by the method of Becker et al. (1).

ISP methods. The methods and media recommended by the International Streptomyces project (ISP) for the characterization of Streptomyces species were followed (10), along with certain supplementary tests.

Additional methods. The $\mathrm{pH}$ range for growth was measured with the following buffers at $0.05 \mathrm{M}$ in yeastmalt extract agar plates (ISP no. 2): citric acid, $\mathrm{pH} 3$, 4 , and 5;2[N-morpholino]ethane sulfonic acid (MES), pH 6 (Sigma Chemical Co.); 3[ $\mathrm{N}$-morpholino]-propane sulfonic acid (MOPS), pH 7 (Aldrich Chemical Co.);
$N$-tris-(hydroxymethyl) methyl glycine (Tricine), $\mathrm{pH} 8$ (Calbiochem); 2-(cyclohexylamino)ethanesulfonic acid (CHES), pH 8.5, 9.0, and 9.5 (P-L Biochemicals, Inc.); and 3-cyclohexylamino-1,1-propane sulfonic acid (CAPS), $\mathrm{pH} 10.0$ and 10.5 . The $\mathrm{pH}$ values of the agar plates were measured with a flat-surface electrode before inoculation.

Carbon utilization was determined on ISP no. 9 basal medium to which filter-sterilized carbon sources were added to achieve a final concentration of $1.0 \%$. Plates were incubated at $30^{\circ} \mathrm{C}$ and read after 14 days.

Melanoid pigment production was determined in ISP no. 1 (tryptone-yeast extract broth), ISP no. 6 (peptone-yeast extract-iron agar), ISP no. 7 (tyrosine agar), and modified ISP no. 7 (lacking tyrosine).

Starch hydrolysis was determined by testing for the presence of starch with iodine on ISP no. 4 (inorganic salts-starch agar) plates (3).

Lysozyme resistance and decomposition of casein, esculin, hypoxanthine, tyrosine, and xanthine were measured by the procedure of Berd (2).

$\mathrm{NaCl}$ and sucrose tolerance were measured with ISP no. 2 agar. Antibiotic susceptibility was determined with susceptibility disks placed onto the surface of ISP no. 2 agar plates seeded with $2 \%$ vegetative inoculum.

The methods of Blazevic and Ederer (3) were followed for the catalase, phosphatase, and urease assays.

The Inter-science Color Council-National Bureau of Standards (ISCC-NBS) Centroid color charts, standard sample no. 2106 (13), were used to assign color names to the pigments produced.

Similarity coefficients were calculated from the equation (6) $\mathrm{S}=\left[\mathrm{Ns}^{+}+\mathrm{Ns}^{-}\right] /\left[\mathrm{Ns}^{+}+\mathrm{Ns}^{-}+\mathrm{Nd}\right] \times$ 100 , where $\mathrm{Ns}^{+}$is the number of positive similarities, $\mathrm{Ns}^{-}$is the number of negative similarities, and $\mathrm{Nd}$ is the number of dissimilarities (differences).

\section{RESULTS}

Morphological characteristics. Strain A49492 produced well-developed, coiled, aerial mycelia, and it was therefore placed in the Spirales (S) section of the classification of Pridham et al. (9). This morphology was readily observed on all media which support formation of aerial mycelia. Oatmeal agar (ISP no. 3), ISP no. 7, tomato 

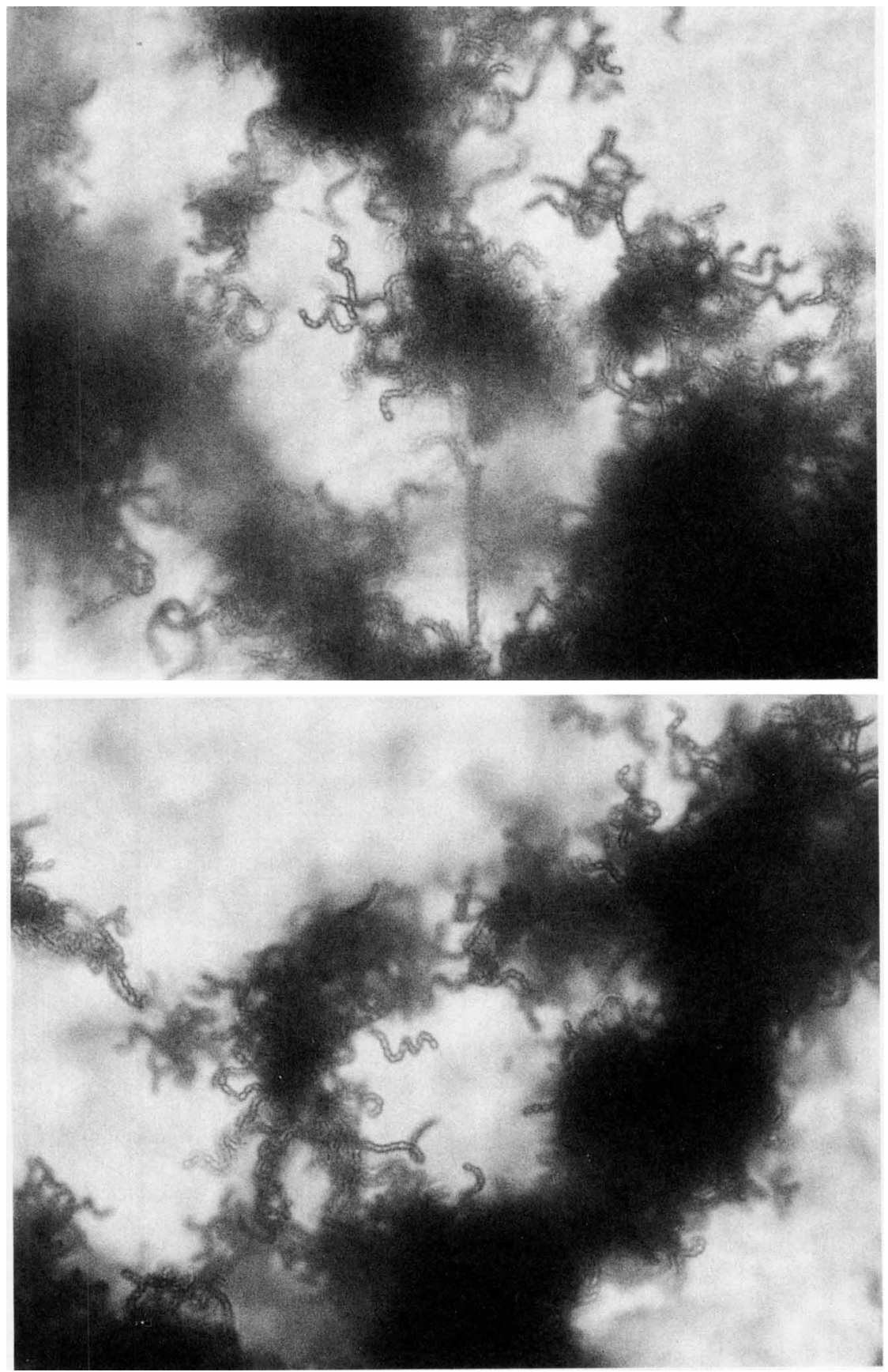

FIG. 1. Spore-bearing aerial hyphae of strain A49492: composite of two photographs exhibiting spiral morphology. The organism was viewed with an optical microscope at $\times 400$. The figure shows an undisturbed habitat on ISP no. 3 (incubated for 14 days at $30^{\circ} \mathrm{C}$ ). 


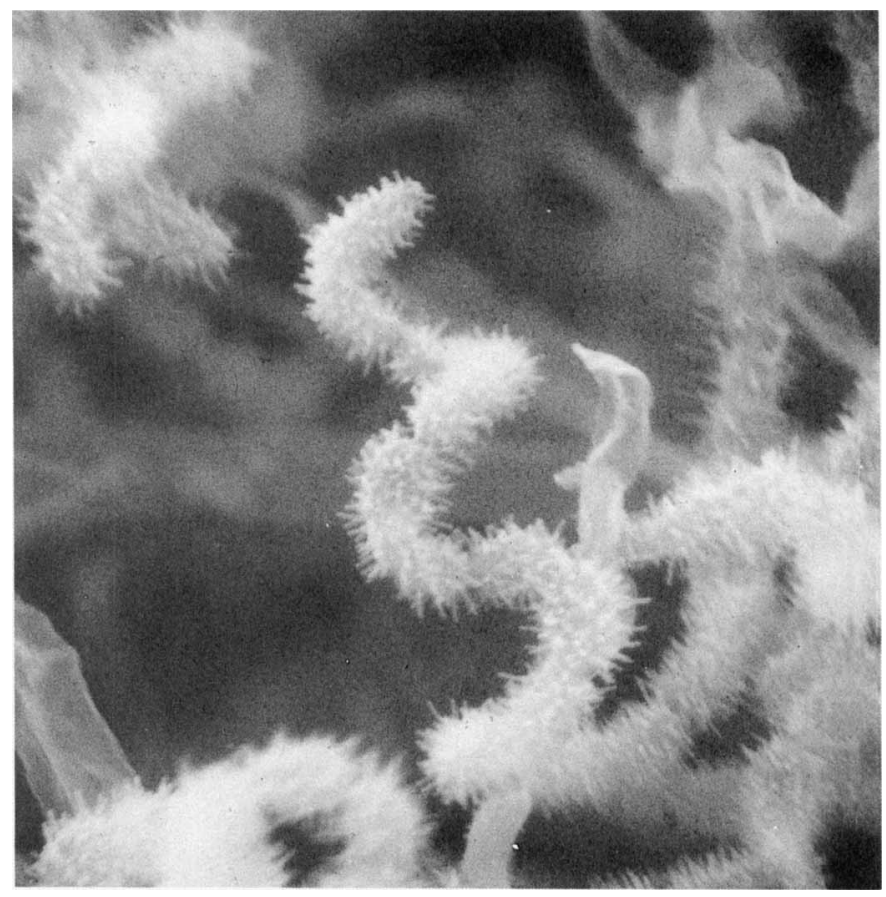

FIG. 2. Spiral morphology of strain A49492 on tomato paste oatmeal agar, seen with a scanning electron microscope at $\times 10,000$. The organism was incubated for 14 days at $30^{\circ} \mathrm{C}$. Bar, $1.0 \mu \mathrm{m}$.

paste oatmeal agar, and tap-water agar provided excellent observation of spiral morphology (Figs. 1 and 2). The spirals were simple, open, loose coils of two to three turns. The sporophores bore chains of 10 to 50 spores. Scanning electron micrographs indicated that the spore shape was oval to globose (Fig. 3). The spore size ranged from 0.96 to $1.19 \mu \mathrm{m}$ by 0.54 to 0.71 $\mu \mathrm{m}$. The average size was 1.05 by $0.62 \mu \mathrm{m}$. The spore surface ornamentation was hairy (Fig. 4). Coremia were observed on yeast-malt extract agar (ISP no. 2).

Cultural characteristics. The aerial mycelium was in the gray (GY) color series of Tresner and Backus $(12,13)$; light brownish-gray was the predominant shade. Strain A49492 produced a nonfragmenting substrate or primary mycelium which varied from yellow-brown to brownishblack, depending on the medium. A brown, water-soluble pigment was occasionally produced. The strain did not produce melanoid pigments.

Physiological characteristics. The physiological characteristics of strain A49492 are as follows. Catalase, phosphatase, and urease were positive; casein, hypoxanthine, tyrosine, and xanthine were decomposed. Liquefaction of gelatin, hydrolysis of starch, reduction of nitrate, peptonization of milk, resistance to lysozyme, and decomposition of esculin were negative.
Acetate, D-arabinose, melibiose, raffinose, salicin, and sucrose were not utilized. Growth of A49492 occurred within a temperature range of 10 to $45^{\circ} \mathrm{C}$, with an optimum of $30^{\circ} \mathrm{C}$. A49492 tolerated a pH range of 6 to 9.5 , levels of $\mathrm{NaCl}$ up to $6 \%$, and sucrose concentrations up to $35 \%$.

Analysis of cell wall hydrolysates by paper chromatography demonstrated the presence of LL-diaminopimelic acid. No meso isomer was detected. Sugar determinations indicated that only glucose and ribose were present. This information indicates a type I cell wall and a type C sugar pattern (4). The morphological and chemical characteristics of strain A49492 permit a clear assignment of the organism to the genus Streptomyces.

A comparison of the characteristics of strain A49492 with the published descriptions of the currently recognized Streptomyces species indicated which species are most closely related (Table 1).

The six Streptomyces species listed in Table 1 were reported as belonging in the (GY) color series (13), with spiral (S) (9) sporophore morphology, hairy spore surface ornamentation, and a carbon utilization pattern similar to that of A49492. These reference strains were grown simultaneously with culture A49492 to obtain laboratory comparisons.

The similarity coefficients for each of the 


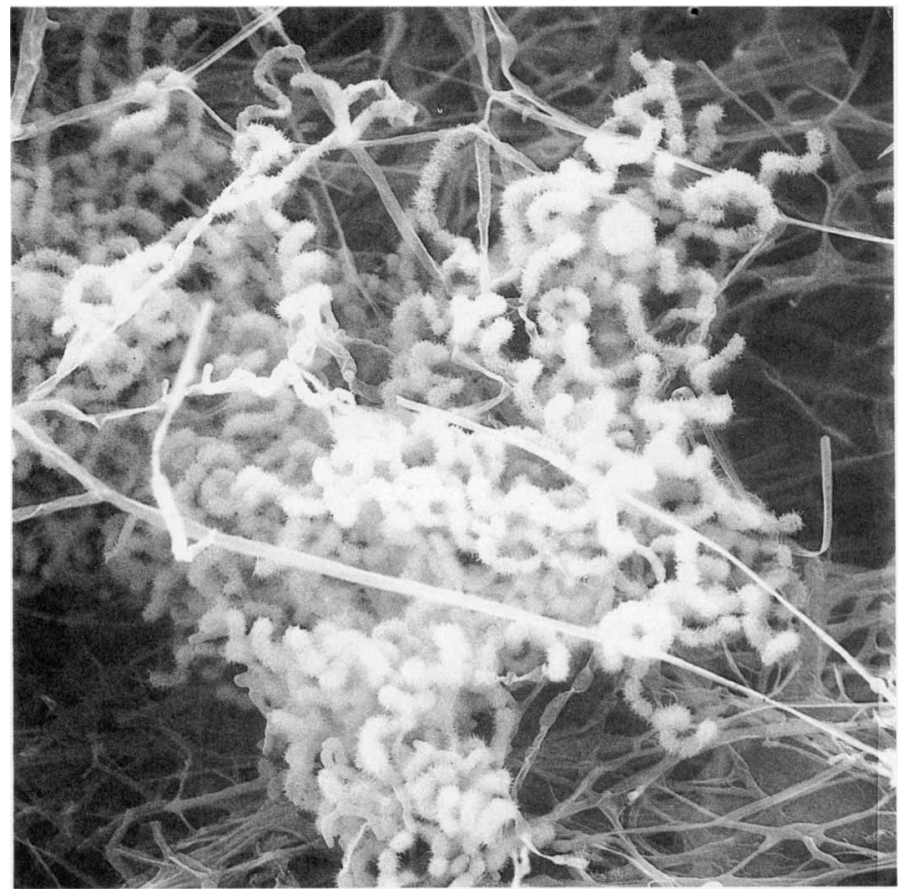

FIG. 3. Spore shape of strain A49492 on ISP no. 7 (tyrosine agar), seen with a scanning electron microscope at $\times 2,000$. The organism was incubated for 14 days at $30^{\circ} \mathrm{C}$. Bar, $10.0, \mu \mathrm{m}$.

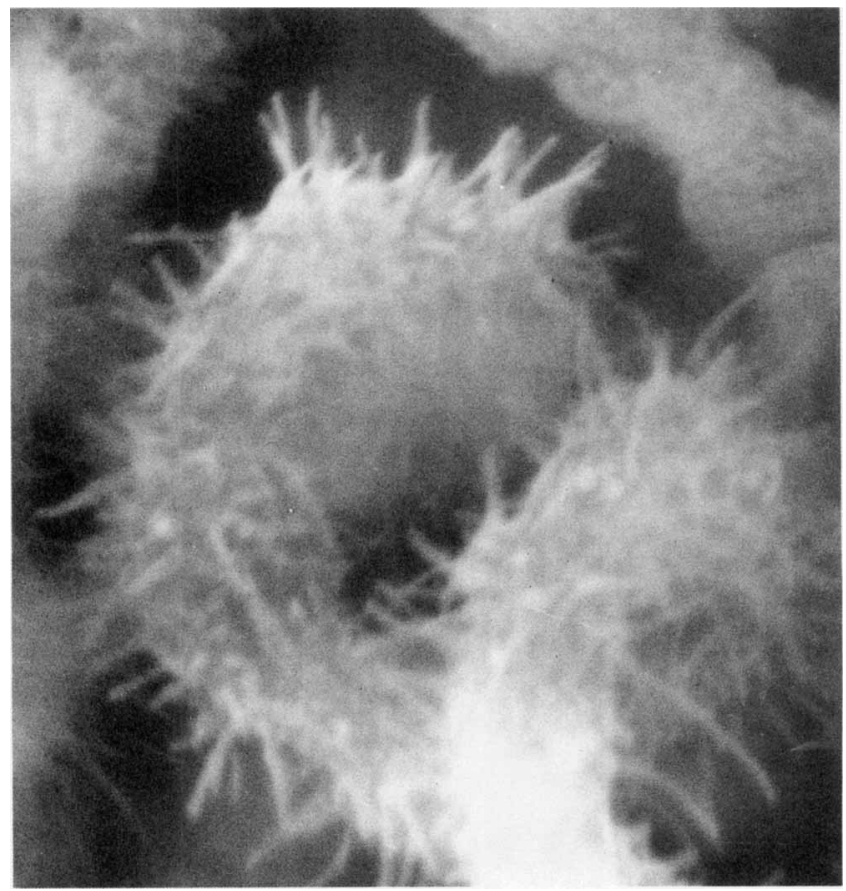

FIG. 4. Hairy spore surface ornamentation of strain A49492 on ISP no. 7 (tyrosine agar), seen with a scanning electron microscope at $\times 30,000$. The organism was incubated for 14 days at $30^{\circ} \mathrm{C}$. Bar, $0.1 \mu \mathrm{m}$. 
TABLE 1. Strain A49492 and six Streptomyces reference strains used in this study

\begin{tabular}{lcc}
\hline \multicolumn{1}{c}{ Strain $^{a}$} & $\begin{array}{c}\text { ATCC } \\
\text { no. }\end{array}$ & $\begin{array}{c}\text { Coefficient } \\
\text { of similarity }\end{array}$ \\
\hline A49492 & & 100 \\
S. calvus & 13382 & 67 \\
S. flaveolus & 3319 & 67 \\
"S. flavoviridis", & 19903 & 69 \\
"S. heimi" & 25460 & 67 \\
"S. malachitofuscus", & 25471 & 71 \\
S. pilosus & 19797 & 67 \\
\hline
\end{tabular}

${ }^{a}$ Names in quotation marks were not on the Approved Lists of Bacterial Names (11) and have not been validly published since 1 January 1980 .

reference strains when compared with strain A49492 are given in Table $1 . \mathrm{Ns}^{+}$is the number of positive similarities, $\mathrm{Ns}^{-}$is the number of negative similarities, and $\mathrm{Nd}$ is the number of dissimilarities. The total units of measurement $\left(\mathrm{Ns}^{+}+\mathrm{Ns}^{-}+\mathrm{Nd}\right)$ were 152 . This figure was composed of morphological and physiological characters. When only morphological characters were used, "S. flavoviridis" ATCC 19903 had the highest coefficient of similarity, but when both morphological and physiological characters were used, " $S$. malachitofuscus" ATCC 25471 had the greater number of common characters of similarity to A49492, as is shown in Table 1.

Table 2 lists in brief the similarities and differences among strain A49492, "S. flavoviridis" ATCC 19903, and "S. malochitofuscus" ATCC 25471.

The growth characteristics and pigmentation of all of the strains studied are presented in Table 3. The color notations are from the ISCCNBS Centroid color charts (13).

Strain A49492 was also compared with six Streptomyces species with respect to carbohydrates utilization patterns and antibiotic susceptibility. The data for carbohydrate utilization are presented in Table 4, and the antibiotic susceptibilities of these strains are given in Table 5 .

Further comparisons were made with a number of other tests. Table 6 gives a summary of the results from these additional studies.

\section{DISCUSSION}

Streptomyces has been the most extensively studied and exploited genus of the Actinomycetales. This is due to its medical and industrial utility. Consequently, many new species have been suggested for this genus. Differences between strains are not hard to find; indeed, the more characters determined, the greater the number of differences observed (5). Therefore, the temptation to erect new species must be resisted. A conservative approach that is not based on occasional differences is preferable.

Strain A49492 exhibited considerable differences in relation to six Streptomyces species with which it was compared. These differences are not just occasional but, as Table 3 indicates, significant. Strain A49492 differs from "S. flavoviridis" ATCC 19903 and "S. malochitofuscus" ATCC 25471, the two organisms most similar, in growth, pigmentation, carbon utilization, $\mathrm{NaCl}$ and sucrose tolerance, $\mathrm{pH}$ range, urease production, and ability to decompose certain substrates.

TABLE 2. Differences and similarities among strain A49492, "S. flavoviridis" ATCC 19903, and "S. malachitofuscus" ATCC 25471 ${ }^{a}$

\begin{tabular}{ll}
\hline \multicolumn{1}{c}{ Similarity } & \multicolumn{1}{c}{ Difference } \\
\hline Antibiotic susceptibility (see Table 5) & \multicolumn{1}{c}{ Carbon utilization (see Table 4) } \\
Casein decomposition positive & Growth on various agar and liquid media \\
Catalase test positive & Melanoid pigment absent in A49492 \\
Gelatin liquefaction negative & NaCl toleration less for A49492 \\
Lysozyme susceptibility & Soluble pigment produced by A49492 \\
Morphology (spiral sporophores) & Spore hair density greater in A49492 \\
Nitrate reduction negative & Sucrose tolerance less for A49492 \\
Optimal growth on Bennett agar & Urease production by A49492 \\
Phosphatase test positive & Esculin decomposition \\
Skim milk, slight hydrolysis & Hypoxanthine decomposition \\
Spore mass color, gray & Xanthine decomposition \\
Spore surface, hairy & pH range \\
Starch hydrolysis negative & \\
Temperature range, $10-45^{\circ} \mathrm{C}^{b}$ & \\
Tyrosine decomposition positive & \\
\hline
\end{tabular}

${ }^{a}$ Names in quotation marks were not on the Approved Lists of Bacterial Names (11) and have not been validly published since 1 January 1980.

b "S. flavoviridis" only. 


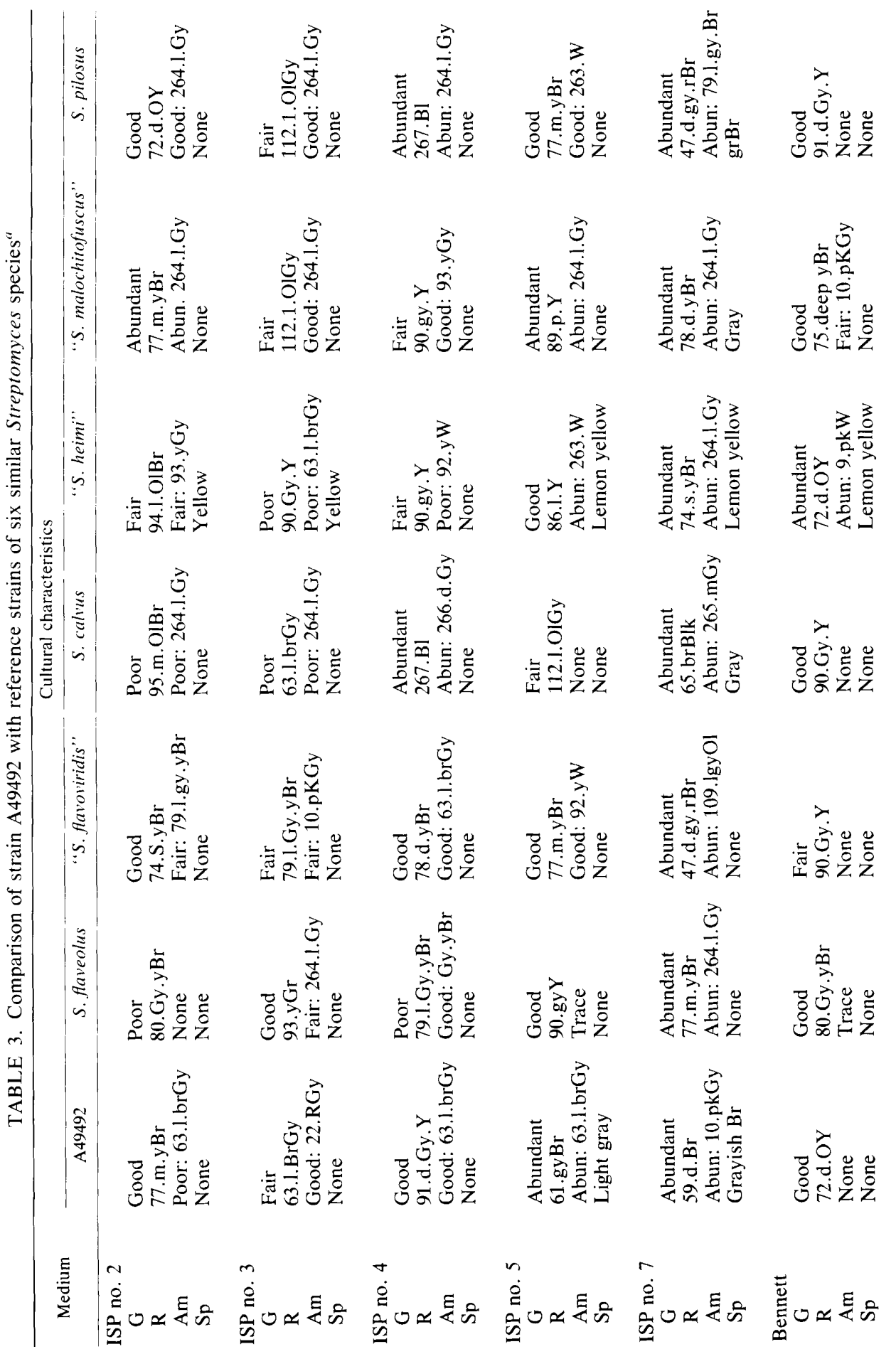




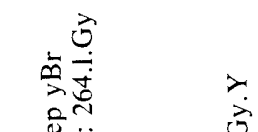

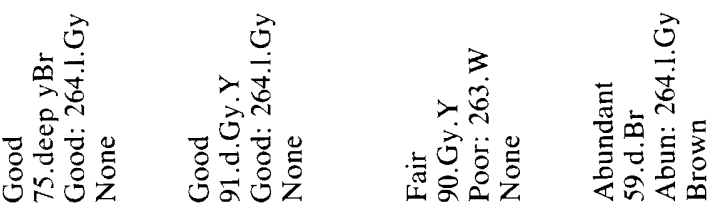

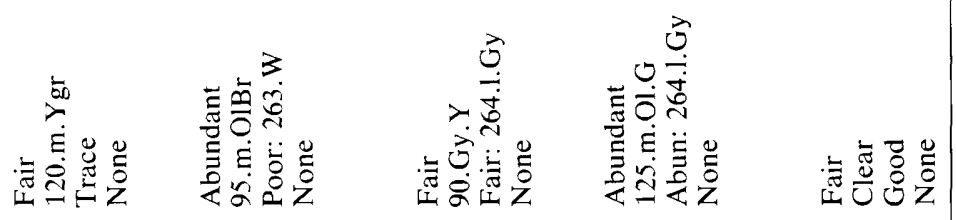

衰龍影

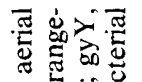

䒕需出

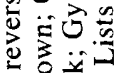

年

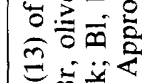

象言苟

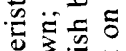

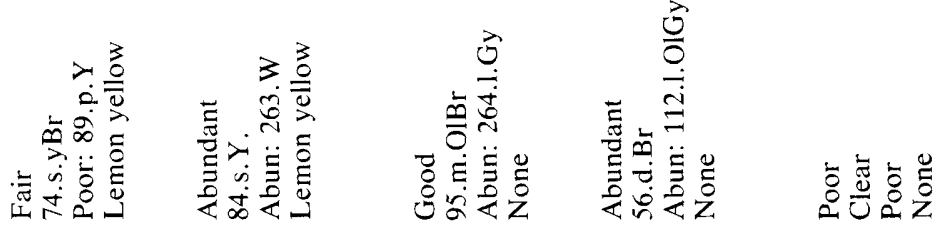

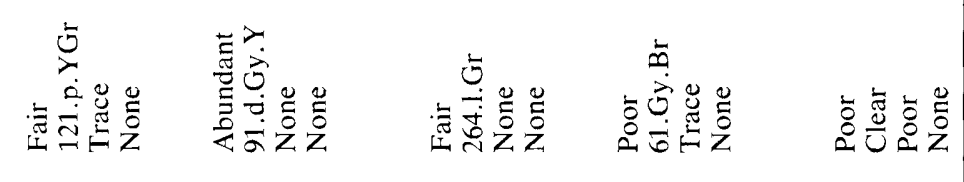

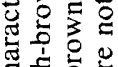

चै.

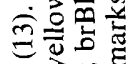

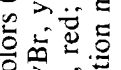

泀范

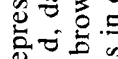

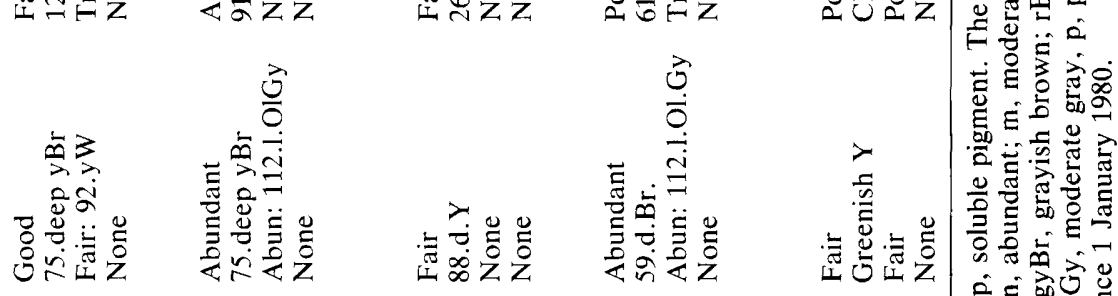

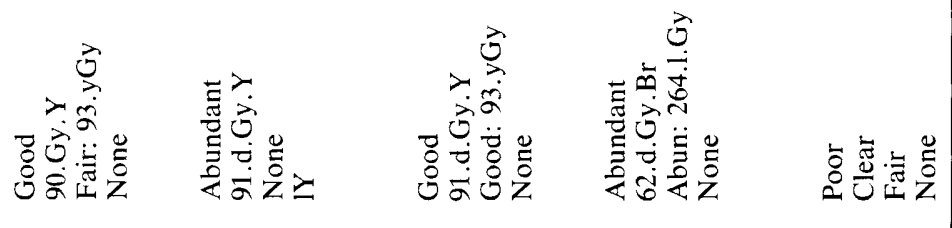

की

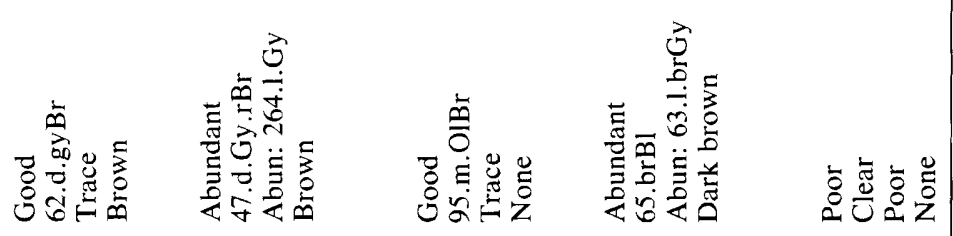

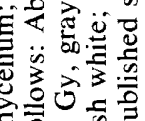

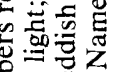

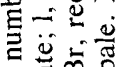


TABLE 4. Carbon utilization by strain A49492 and six similar reference strains of Streptomyces species ${ }^{a}$

\begin{tabular}{|c|c|c|c|c|c|c|c|}
\hline \multirow{2}{*}{$\begin{array}{l}\text { Carbon } \\
\text { source }\end{array}$} & \multirow{2}{*}{ A49492 } & \multicolumn{6}{|c|}{ ATCC no. } \\
\hline & & 3319 & 19903 & 13382 & 25460 & 25471 & 19797 \\
\hline Control & - & - & - & - & - & - & - \\
\hline Acetate & - & - & + & - & - & - & + \\
\hline D-Arabinose & - & - & - & + & - & - & - \\
\hline L-Arabinose & + & + & + & $(+)$ & + & + & + \\
\hline Cellobiose & + & + & + & + & + & + & + \\
\hline Citrate & + & + & + & $(+)$ & $(+)$ & + & + \\
\hline D-Fructose & + & + & + & + & + & + & + \\
\hline D-Galactose & + & + & + & + & + & + & + \\
\hline D-Glucose & + & + & + & + & + & + & + \\
\hline$i$-Inositol & + & + & + & + & + & + & + \\
\hline D-Maltose & + & + & + & + & + & + & + \\
\hline D-Mannitol & + & + & + & + & + & + & + \\
\hline Melibiose & - & - & - & $(+)$ & - & - & - \\
\hline Raffinose & - & + & - & + & - & - & - \\
\hline Rhamnose & + & + & + & + & + & + & + \\
\hline D-Ribose & + & + & + & + & + & + & + \\
\hline Salicin & $(+)$ & + & - & - & t & - & - \\
\hline Sucrose & - & + & - & + & + & + & - \\
\hline D-Xylose & + & + & + & + & + & + & + \\
\hline
\end{tabular}

\footnotetext{
a Symbols: + , positive utilization (carbon source used); - , negative utilization (carbon source not used); $(+)$,
} questionable utilization.

The coefficient of similarity between strain A49492 and the six compared species is low (Table 1). "S. malochitofuscus" ATCC 25471 was the most similar to A49442, with a coefficient of 71. However, this similarity is insufficient to consider A49492 to be a strain of " $S$. malochitofuscus."

The coefficients of similarity when these six species were compared with one another rather than with strain A49492, were of the same general order as when they were compared with strain A49492. For instance, the coefficient of similarity when $S$. pilosus ATCC 19797 was compared with "S. favoviridis" ATCC 19903 was 75 . The other five reference strains of Streptomyces species, when compared with " $S$. flavoviridis" ATCC 19903, had coefficients of similarity which were less than 75 . Therefore, we suggest that strain A49492, which has a low similarity to the reference strains studied, be regarded as a member of a new species, for which the name Streptomyces capillispiralis sp. nov. is proposed (ca.pil-li-spi-ra' lis; L. n. capillus hair; L. adj. spiralis spiral or spiraled; M.L. adj. capillispiralis hairy-spiraled). The type strain is A49492 (7). A culture of this strain has been deposited at the Northern Regional Research Center, Peoria, Ill., under the accession number 12279.

The descriptions of the species and of the type strain are the same as that given above and in Tables 4 through 6 for strain A49492.

TABLE 5. Comparison of the antibiotic susceptibility of strain A49492 with those of the six similar reference strains of the Streptomyces species studied ${ }^{a}$

\begin{tabular}{|c|c|c|c|c|c|c|c|c|}
\hline Antibiotic (type) & Concn $^{b}$ & A49492 & $\begin{array}{c}\text { ATCC } \\
3319\end{array}$ & $\begin{array}{c}\text { ATCC } \\
19903\end{array}$ & $\begin{array}{c}\text { ATCC } \\
13382\end{array}$ & $\begin{array}{c}\text { ATCC } \\
25460\end{array}$ & $\begin{array}{c}\text { ATCC } \\
25471\end{array}$ & $\begin{array}{l}\text { ATCC } \\
19797\end{array}$ \\
\hline Erythromycin (macrolide) & $15 \mu \mathrm{g}$ & - & + & - & + & - & - & - \\
\hline Cephalothin ( $\beta$-lactam) & $30 \mu \mathrm{g}$ & - & - & - & - & - & - & - \\
\hline Lincomycin (lincosaminide) & $2 \mu \mathrm{g}$ & - & - & - & - & - & - & - \\
\hline Nystatin (polyene) & $100 \mathrm{U}$ & - & - & - & - & - & - & - \\
\hline Polymyxin B (peptide) & $300 \mathrm{U}$ & - & - & - & - & - & - & - \\
\hline Streptomycin (aminoglycoside) & $10 \mu \mathrm{g}$ & + & + & + & + & + & + & + \\
\hline Tetracycline (perhydronaphthacene) & $30 \mu \mathrm{g}$ & + & + & + & + & + & + & + \\
\hline Vancomycin (glycopeptide) & $5 \mu \mathrm{g}$ & + & + & + & + & + & + & + \\
\hline
\end{tabular}

${ }^{a}$ Symbols: + , susceptible (zones of inhibition); - , resistant (no zones of inhibition).

${ }^{b}$ Amount of antibiotic per disk. 
TABLE 6. Comparison of strain A49492 with six similar reference strains of Streptomyces species ${ }^{a}$

\begin{tabular}{|c|c|c|c|c|c|c|c|}
\hline Test & A49492 & $\begin{array}{c}\text { ATCC } \\
3319\end{array}$ & $\begin{array}{c}\text { ATCC } \\
19903\end{array}$ & $\begin{array}{c}\text { ATCC } \\
13382\end{array}$ & $\begin{array}{c}\text { ATCC } \\
25460\end{array}$ & $\begin{array}{c}\text { ATCC } \\
25471\end{array}$ & $\begin{array}{c}\text { ATCC } \\
19797\end{array}$ \\
\hline $\begin{array}{l}\text { Temperature range for } \\
\text { growth }\left({ }^{\circ} \mathrm{C}\right)\end{array}$ & $10-45$ & $10-45$ & $10-45$ & $15-50$ & $15-45$ & $15-45$ & $5-45$ \\
\hline $\mathrm{pH}$ range for growth & $6-9.5$ & $6-9$ & $6-9.7$ & $6-9.5$ & $6-9$ & $6-9.5$ & $6-9.7$ \\
\hline $\mathrm{NaCl}$ tolerance $(\%)$ & 6 & 8 & 8 & 6 & 6 & 10 & 6 \\
\hline Sucrose tolerance $(\%)$ & 35 & 30 & 50 & 35 & 35 & 40 & 35 \\
\hline Catalase & + & + & + & + & + & + & + \\
\hline Phosphatase & + & + & + & + & + & + & + \\
\hline Urease & + & + & - & -- & + & - & - \\
\hline Nitrate reductase & - & - & - & - & - & - & - \\
\hline Gelatin liquefaction & - & - & - & -- & - & - & + \\
\hline Melanoid pigments & - & - & + & - & - & + & + \\
\hline Skim milk & $(+)$ & $(+)$ & $(+)$ & + & - & $(+)$ & $(+)$ \\
\hline Starch hydrolysis & - & - & - & - & - & - & - \\
\hline Lysozyme resistance & - & $(+)$ & - & $(+)$ & $(+)$ & - & - \\
\hline Casein decomposition & + & + & + & + & + & + & + \\
\hline Esculin decomposition & - & + & + & + & - & - & + \\
\hline Hypoxanthine decomposition & + & + & - & + & + & + & - \\
\hline Tyrosine decomposition & + & + & + & + & + & + & + \\
\hline Xanthine decomposition & + & + & - & + & + & + & - \\
\hline Morphology & $S$ & $\mathrm{~S}$ & $\mathrm{~S}$ & $\mathrm{~S}$ & $\mathrm{~S}$ & $\mathrm{~S}$ & $\mathrm{~S}$ \\
\hline Spore surface & $\mathrm{H}$ & $\mathrm{H}$ & $\mathrm{H}$ & $\mathbf{H}$ & $\mathrm{H}$ & $\mathrm{H}$ & $\mathrm{H}$ \\
\hline Spore size $(\mu \mathrm{m})$ & $\begin{array}{c}1.05 \text { by } \\
0.62\end{array}$ & $\begin{array}{c}1.06 \text { by } \\
0.75\end{array}$ & $\begin{array}{c}0.92 \text { by } \\
0.65\end{array}$ & $\begin{array}{c}0.98 \text { by } \\
0.63\end{array}$ & $\begin{array}{c}0.93 \text { by } \\
0.93\end{array}$ & $\begin{array}{c}0.87 \text { by } \\
0.68\end{array}$ & $\begin{array}{c}0.81 \text { by } \\
0.71\end{array}$ \\
\hline
\end{tabular}

a Symbols: + , positive reaction; --, negative reaction; $(+)$, partial reaction (for lysozyme, symbol indicates equivocal results); $\mathrm{S}$, spiral; $\mathrm{H}$, hairy.

\section{ACKNOWLEDGMENTS}

We thank Richard A. Schlegel, Eli Lilly \& Co., Indianapolis, Ind., for skillful technical assistance in obtaining the scanning electron micrographs.

\section{REPRINT REQUESTS}

Address reprint requests to: F. P. Mertz, The Lilly Research Laboratories, Eli Lilly \& Co., Indianapolis, IN 46285.

\section{LITERATURE CITED}

1. Becker, B., M. P. Lechevalier, R. E. Gordon, and H. A. Lechevalier. 1964. Rapid differentiation between Nocardia and Streptomyces by paper chromatography of whole-cell hydrolysates. Appl. Microbiol. 12:421-423.

2. Berd, D. 1973. Laboratory identification of clinically important aerobic actinomycetes. Appl. Microbiol. 25:665-681.

3. Blazevic, D. J., and G. M. Ederer. 1975. Principles of biochemical tests in diagnostic microbiology. John Wiley \& Sons, Inc., New York.

4. Gottlieb, David. 1974. Order I. Actinomycetales Buchanan 1917, 162, p. 157-159. In R. E. Buchanan and N. E. Gibbons (ed.), Bergey's manual of determinative bacteriology, 8th ed. The Williams \& Wilkins Co., Baltimore

5. Gottlieb, D., and E. B. Shirling. 1976. An evaluation of the international Streptomyces project, p. 1-7. In T. Arai (ed.), Actinomycetes the boundary microorganisms. Tappen Co. Ltd., Tokyo.
6. Kurylowicz, W., A. Paszkiewicz, W. Woznicka, W. Kurzatkowski, and T. Szulga. 1975. Numerical taxonomy of streptomycetes, p. 36-44. Polish Medical Publishers, Warsaw.

7. Lapage, S. P., P. H. A. Sneath, E. F. Lessel, V. B. D. Skerman, H. P. R. Seeliger, and W. A. Clark (ed.). 1975. International code of nomenclature of bacteria. $1975 \mathrm{Revi}$ sion, p. 18-20. American Society for Microbiology, Washington, D.C.

8. Lechevalier, M. P. 1968. Identification of aerobic actinomycetes of clinical importance. J, Lab. Clin. Med. 71:934944.

9. Pridham, T. G., C. W. Hesseltine, and R. G. Benedict. 1958. A guide for the classification of streptomycetes according to selected groups. Placement of strains in morphological sections. Appl. Microbiol. 6:52-79.

10. Shirling, E. B., and D. Gottlieb. 1966. Methods for characterization of Streptomyces species. Int. J. Syst. Bacteriol. 16:313-340.

11. Skerman, V. B. D., V. McGowan, and P. H. A. Sneath (ed.). 1980. Approved lists of bacterial names. Int. J. Syst. Bacteriol. 30:225-420.

12. Tresner, H. D., and E. J. Backus. 1963. System of color wheels for streptomycete taxonomy. Appl. Microbiol. 11:335-338.

13. U.S. Department of Commerce, National Bureau of Standards. 1958. ISCC-NBS Centroid color charts standard sample no. 2106. U.S. Department of Commerce, Washington, D.C. 